\title{
Examining the Relationship between Career Outcome Expectations and Physics Identity
}

\author{
Camila Monsalve $^{1}$, Zahra Hazari ${ }^{123}$, Daryl McPadden ${ }^{1}$, Gerhard Sonnert ${ }^{4}$, and Philip M. Sadler ${ }^{4}$ \\ ${ }^{1}$ Department of Physics, ${ }^{2}$ Department of Teaching and Learning, ${ }^{3}$ STEM Transformation Institute, \\ Florida International University, 11200 SW 8th St., Miami, FL 33199, \\ 4Science Education Department, Harvard-Smithsonian Center of Astrophysics,60 Garden St., Cambridge, MA \\ 02138
}

Previous studies about career outcome expectations, or what students hope to achieve in their careers, have revealed strong relationships between outcome expectations and STEM career choice. Drawing from a US national survey with responses from 15,847 students in mandatory College English courses (Outreach Programs and Science Career Intentions, NSF \# 1161052), we examined the relationship between students outcome expectations and physics identity. It has previously been found that students with certain outcome expectations are more likely to develop a physics identity. Expanding beyond prior work, we focus on how outcome expectations are related to physics identity for students grouped by: (i) medical and engineering career aspirations, and (ii) female and male self-identification. The results provide a more nuanced understanding of the relationship between outcome expectations and physics identity for different students.

\section{INTRODUCTION}

What students value in their life and what they hope to achieve as a result of this valuing is strongly related to how they see themselves and the types of careers they choose to pursue [1]. As such, this study examines the relationship between what students hope to achieve in their careers (outcome expectations) and how they see themselves with respect to physics (physics identity). We focus on physics identity as an outcome because seeing oneself as a "physics person" has been found to be strongly related to persistence in physics [2]. Furthermore, we advance beyond prior work through a more nuanced examination that compares different stakeholding groups in physics. These groups include the largest groups of students who are required to take physics but are not physics majors, specifically pre-medical and engineering students. We also compare by gender groups, specifically female and male, since female students have been found to have lower physics identities than their male counterparts [2]; this gender difference spans multiple race/ethnicity groups including white students, black students, and Hispanic students [3]. Thus, it is important to understand how outcome expectations might mediate identity development for female students in particular.

\section{OUTCOME EXPECTATIONS}

Career outcome expectations are defined as the outcomes which students hope to achieve as part of their careers. Examples include outcomes such as making money, learning new skills, working with others, etc. Outcome expectations are important because they frame how students value a certain activity (e.g. learning physics) based on what they hope to achieve, which in turn influences students' motivation and persistence when engaging in that activity $[1,4-7]$. Prior work has not only found connections between outcome expectations and interest but also between outcome expectations and physics identity $[2,4,5,7]$. More specifically, students who were intrinsically motivated when choosing a career (e.g. allowing them to invent new things, make use of talents/abilities, develop new knowledge/skills) identified more strongly with physics than those who did not seek such careers [2]. In contrast, students who sought people-related outcomes (e.g. helping other people and working with people) were less likely to identify with physics than their counterparts without these career expectations.

The match/mismatch between certain outcome expectations and having a physics identity is likely related to students' stereotypic perceptions of the field of physics and those who participate in it. For example, one study that examined 30 different fields found that physics is one of the fields that is associated with innate brilliance [8]. Another study found that physical/mathematical sciences are seen as being less able to afford goals that involve other people [9]. Students may think instead of the "lone scientist" or "technology and machinery" [10]. Finally, individuals have been found to align their interests and aspirations to those that coincide with the roles that society has ascribed for them [10]. For example, women maintain high association levels with communal roles (caring for other people) and physics is not perceived as communal such that "even scientifically talented women frequently choose other careers" [10].

\section{PHYSICS IDENTITY}

Our physics identity framework is one that has extensively been drawn upon in physics education and more broadly in STEM education [2, 11-13]. The theory originally posited four underlying sub-constructs that were important for physics identity development: perceptions of competence, ability to perform, recognition by others, and interest [2]. Research-based refinements of the theory uncovered that perceptions of competence and ability to perform are not delineated for students, nor do these have a direct effect on physics identity [13]. In line with this work, our study considers only the two sub-constructs of recognition and interest as directly indicative of a students' physics identity. Finally, since we draw on survey 
data, our work takes a "narrated" approach (reported by students themselves) in studying identity rather than a "performed" approach (observations of what students do and say) [14]. However, both approaches are seen as equally valid as well as complimentary when studying identity construction in science education.

For this study, we asked the following research question: How do students' career expectations relate to their physics identity (1) for students overall, (2) for students with pre-medical or engineering career interests, and (3) for female versus male students?

\section{METHODS}

This study draws on data from a national survey study entitled "Outreach Programs and Science Career Intentions (OPSCI)" administered to students in required introductory College English courses. This allowed us to capture the natural variation in experiences of students in STEM majors versus those who were not in STEM. Surveys were collected from 15,847 students at 27 colleges and universities, located in 20 different states. Within this population, there were 8033 female students and 6315 male students (female response was coded as 0 and male response as 1). Furthermore, there were 2341 premeds, 596 engineers and 68 reporting both career intentions, leaving 12842 who reported other careers. The survey was tested for both reliability and validity. A test-retest study administered to 57 students yielded a reliability of 0.73 (average correlation) with a reliability of 0.82 for the physics identity items. Face and content validity were established through feedback from an advisory team of science education experts. Construct validity for the physics identity items and outcome expectations were established through factor analyses.

Outcome expectations were initially collected through fifteen items on the OPSCI survey. Students rated items, such as "making money" or "having lots of family time", on a zero to five scale, in which zero indicated "not important" and five indicated "very important" for their future career satisfaction. Through factor analysis, eight items were removed because the loadings were not above 0.5 with the theorized factors [2]. The remaining seven items loaded onto three theorized factors: extrinsic social, extrinsic economic, and intrinsic. Extrinsic social clustered the items of working with people and helping people. Extrinsic economic clustered having many job opportunities, a secure job in their field, and making money. Intrinsic outcome expectation clustered having an exciting job and being able to use one's talents.

Physics identity was measured with eight items from OPSCI. Factor analysis revealed that the eight items aligned to the two theorized factors of physics interest and physics recognition, four items in each. An example for each factor is "I enjoy learning about physics" and "My physics teacher sees me as a physics person." Since the items were evenly split between both factors, all eight items were averaged to create the physics identity proxy.
To analyze the data, we used linear regression analysis to examine how career outcome expectations predict students' physics identity. Also, we used backward elimination to remove non-significant outcome expectations. In Model 1, we analyzed how intrinsic, extrinsic social and extrinsic economic factors related to students' physics identity. In Model 2, we examined two groups, pre-medical and engineering students, with respect to how outcome expectations relate to their physics identity by including interaction effects in the model. The interaction effects indicate whether there is a significant difference in the groups' slopes. In Model 3, we analyzed the effect of outcome expectations on physics identity for male versus female students with interaction effects.

\section{RESULTS AND DISCUSSIONS}

\section{A. Model 1}

The first linear model we tested predicted physics identity with outcome expectations (extrinsic social, extrinsic economic, and intrinsic). These regression results are summarized in Table I. We found that physics identity is positively related with intrinsic outcome expectations in physics at a highly significant level. This means that students who prioritized having an exciting job and one that uses their talents tended to have higher physics identities. In contrast, we found a highly significant, negative relationship between physics identity and extrinsic social values, meaning students who were interested in helping people and working with others in their future occupations tended to have lower physics identities. Additionally, the effect for extrinsic social was more than double the effect for intrinsic (as seen when comparing standardized estimates, see Table I).

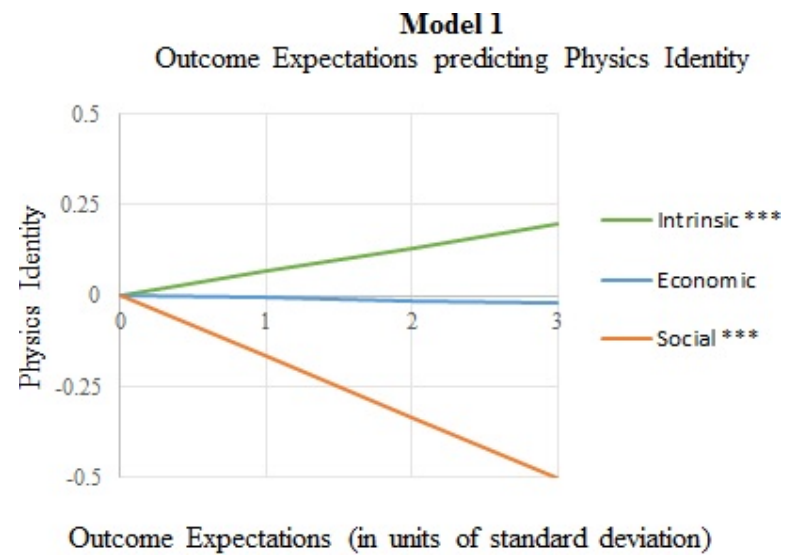

Figure 1. Model 1. Outcome Expectations predict Physics identity. In the key the significance is included, economic was not significant.

\section{B. Model 2}

For Model 2, both the intrinsic and social outcome expectations were still highly significant, with intrinsic positively related and extrinsic social negatively related to 
Table I. Linear regression model for predicting physics identity. Significance (Sig.) are ${ }^{* * *}: \mathrm{p}<0.001 ;{ }^{* *}: \mathrm{p}<0.01 ; *: \mathrm{p}<0.05 ;$. $: \mathrm{p}<0.1 ;$ ns: not significant

\begin{tabular}{|c|c|c|c|c|c|c|c|c|c|c|c|c|}
\hline & \multicolumn{4}{|c|}{ Model 1} & \multicolumn{4}{|c|}{ Model 2} & \multicolumn{4}{|c|}{ Model 3} \\
\hline & \multicolumn{4}{|c|}{ Outcome Expectations } & \multicolumn{4}{|c|}{ Career Choice } & \multicolumn{4}{|c|}{ Gender } \\
\hline Intrinsic & 0.13 & 0.02 & $* * *$ & 0.07 & 0.12 & 0.02 & $* * *$ & 0.06 & 0.12 & 0.02 & *** & 0.06 \\
\hline Extrinsic Social & -0.25 & 0.01 & $* * *$ & -0.17 & -0.25 & 0.01 & $* * *$ & -0.17 & -0.09 & 0.02 & $* * *$ & -0.06 \\
\hline Extrinsic Economic & -0.01 & 0.02 & $\mathrm{~ns}$ & -0.006 & -0.02 & 0.02 & $\mathrm{~ns}$ & -0.011 & -0.01 & 0.02 & ns & -0.005 \\
\hline Social * Pre-Medical & - & - & - & - & 0.14 & 0.04 & $* * *$ & 0.15 & - & - & - & - \\
\hline Intrinsic $*$ Engineer & - & - & - & - & 0.26 & 0.09 & $* *$ & 0.15 & - & - & - & - \\
\hline Economic $*$ Engineer & - & - & - & - & -0.19 & 0.10 & $*$ & -0.11 & - & - & - & - \\
\hline Gender & - & - & - & - & - & - & - & - & 1.35 & 0.11 & $* * *$ & 0.45 \\
\hline Social $*$ Gender & - & - & - & - & - & - & - & - & -0.11 & 0.02 & $* * *$ & -0.14 \\
\hline
\end{tabular}

physics identity. Furthermore, for pre-medical and engineering undergraduates, there were significant interactions: extrinsic social for pre-medicals, intrinsic, and extrinsic economic for engineers.

We found the main effect for pre-medical career intention to be less significant predictor of physics identity (see Table I). However, there was a highly significant interaction effect between pre-medical career intention and extrinsic social on physics identity. Since the interaction estimate is positive, this indicates that having extrinsic social outcome expectations is less negative for pre-meds than it is for non-premeds, although the overall estimate for both groups is still negative. This may imply that premeds have a more static physics identity compared to non-premeds, i.e. their social outcome expectations do not change their physics identity.

We found that engineering career intention does significantly predict physics identity. This indicates that there is a distinction between the physics identities of students who are planning engineering careers and those who are not. This effect is in favor of the engineers since the estimate is positive. The standardized estimates indicate that this is the largest positive effect in the model.

In terms of interactions, the effect between intrinsic and engineering intention was highly significant. Since the estimate was positive, intrinsic expectations are more important for engineers than non-engineers. Thus, engineering students who value using their abilities/talents in their career are more likely to have a physics identity.

Finally, economic career expectations (many job opportunities, a secure job in their field and making money) had a small negative effect on physics identity for engineers (see Table I). Since the estimate was negative, economic expectations have more of a negative effect for engineers than non-engineers.

\section{Model 3}

Model 3 was consistent with the previous models; intrinsic and extrinsic social outcome expectations were highly significant for predicting physics identity and were positively and negatively related, respectively (see Table I). We also found a highly significant main effect for gender which was positive (see Table I). This means that males (coded as "1") tend to have a higher physics identity than females (coded as "0").

As for interactions, only the extrinsic social factor interacted with gender was significant (see Table I). The negative estimate means male students' physics identity decreases more when they value social outcomes expectations for their careers as compared to female students.

\section{CONCLUSION}

In summary, Model 1 reaffirms that physics identity of undergraduates is positively related to intrinsic career expectations and negatively to social career expectations [2]. Since physics identity is highly predictive of the choice of a physics career, one possible interpretation of these results is that Model 1 provides insight into how students view careers in physics. The negative effect of social outcome expectations could suggest that students do not see physical careers as collaborative or as a means to help people, despite the many collaborative projects that physicists develop and investigate (for example: CERN collaboration or NASA) or the discoveries that have social impact (MRI machines, fiber optic cables, etc.) [15]. Furthermore, the positive correlation with an intrinsic drive could be reflecting the belief that careers in physics are for those who are already talented and engaged in physics [8]. This is especially problematic since many students do not take a physics course until later in high school or during their undergraduate careers further limiting their opportunities for early engagement and experiences that would allow them to develop a physics identity at an early time point $[16,17]$. Together, these would mean that the field of physics may be excluding a large population of students because of how physics careers are portrayed and this may reinforce the stereotypical perceptions of physicists. 
In Model 2, we examined the two largest populations of undergraduates in introductory physics courses, premeds and engineering students. Pre-meds may have a more rigid physics identity as seen by the non-significant predictor and the smaller negative effects of social expectation for pre-meds compared to non-premeds. This is important since there are many pre-med students in introductory physics courses who are incredibly talented and interested in physics but may be a challenge to recruit to physics since their physics identities are harder to shift. Additionally, our results imply that pre-meds may not see how physics contributes to their career goals of working with other people and helping people.

Not surprisingly, the physics identity of engineers is generally higher than that of non-engineers. This could be due to similarities between disciplines like the importance of mathematics as well as similar beliefs about ability for both $[8,13]$. Engineering students may also see the direct applicability of physics to engineering. Likewise, the relationship between intrinsic outcome expectations and physics identity is stronger for engineering students.

More problematically, form the negative interaction of engineering and economic outcome expectations, we suggest that engineering students who are economically motivated may not see a physics career as profitable. The need for a profitable career may be greater amongst economically disadvantaged students. Thus, their economic concern for may limit their engagement with physics.

Finally, in Model 3 we examined physics identity as related to outcome expectations when considering the gender of undergraduates. Consistent with previous research, male students tend to have a much higher physics identity than female students. This is problematic since it might limit the participation of women in physics, which is counterproductive when trying to diversify physics and stop the decline of women graduating with a physics major [18]. Additionally, this might be a reflection of the stereotypical view that a physicist can only be male. Furthermore, when considering the negative interaction of gender and social outcome expectations, there may be an additional detriment to physics identity development for males who consider social values to be important in their career. Also, this is aligned to prior work that has found that stereotypic roles for men are more difficult to modify than those for women simply because women's roles have been modified more over time (have been more dynamic) [19]. In other words, since social role expectations such as working with people and helping people are not stereotypically masculine, male students who have social expectations may find it even more difficult to integrate these into physics.

To engage more students in physics careers, stereotypes with regards to what outcomes physics careers can afford need to change. If students continue to develop physics identities based on societal perceptions of physics and physicists, the current state of physics will be perpetuated rather than opening the doors to students who value different things in their life. Learning/engagement that is more socially or economically driven is just as meaningful as that which is purely intrinsically driven. In sum, we suggest that the social impacts of physics careers should be highlighted to begin to make change in perceptions about physics which will help recruit more females and premeds. Similarly, highlighting that careers with a physics undergraduate degree are profitable (higher salaries) as well as stable (lower unemployment) may help recruit more engineering students [20].

\section{ACKNOWLEDGEMENTS}

This material is based upon work supported by NSF Grant No. 1161052. We would like to thank the English professors and students who participated as well as the OPSCI team.
[1] A. Wigfield and J. S. Eccles, Developmental review 12, 265 (1992).

[2] Z. Hazari, G. Sonnert, P. M. Sadler, and M.-C. Shanahan, Journal of Research in Science Teaching 47, 978 (2010).

[3] G. S. Zahra Hazari, Philip M. Sadler, Journal of College Science Teaching 42, 82 (2013).

[4] N. A. Fouad and P. L. Smith, Journal of Counseling Psychology 43, 338 (1996).

[5] N. A. Fouad, P. L. Smith, and K. E. Zao, Journal of Counseling Psychology 49, 164 (2002).

[6] R. W. Lent and S. D. Brown, The Career Development Quarterly 44, 310 (1996).

[7] R. W. Lent, S. D. Brown, and G. Hackett, Journal of vocational behavior 45, 79 (1994).

[8] S.-J. Leslie, A. Cimpian, M. Meyer, and E. Freeland, Science 347, 262 (2015).

[9] C. Morgan, J. D. Isaac, and C. Sansone, Sex Roles 44, 295 (2001).
[10] A. B. Diekman, E. R. Brown, A. M. Johnston, and E. K. Clark, Psychological Science 21, 1051 (2010).

[11] H. B. Carlone and A. Johnson, Journal of research in science teaching 44, 1187 (2007).

[12] J. D. Cribbs, Z. Hazari, G. Sonnert, and P. M. Sadler, Child Development 86, 1048 (2015).

[13] A. Godwin, G. Potvin, Z. Hazari, and R. Lock, Journal of Engineering Education 105, 312 (2016).

[14] J. M. Kane, Science Education 95, 824 (2011).

[15] K. Izlar, Symmetry Magazine (2013).

[16] S. White and C. L. Tesfaye, AIP Statistical Research Center, (April, 2014) (unpublished).

[17] S. White and C. L. Tesfaye, AIP Statistical Research Center, (June, 2014) (unpublished).

[18] T. Hodapp and Z. Hazari, APS News 24 (2015).

[19] A. B. Diekman and A. H. Eagly, Personality and Social Psychology Bulletin 26, 1171 (2000).

[20] P. Mulvey and J. Pold, AIP Statistical Research Center , (2015) (unpublished). 